\title{
Analisis Kohesi Gramatikal Konjungsi dalam Wacana Novel Ayah Karya Andrea Hirata
}

\author{
Ardianna Artati Saputro1 ${ }^{1}$ Endah Ridha Sevira ${ }^{2}$ \\ Institut Agama Islam Negeri (IAIN) Surakarta \\ ardaiannaa@gmail.com ${ }^{1}$, ridhasevira1999@gmail.com²
}

\begin{abstract}
A novel usually tells about human life in interacting with the environment and each other. The method in this study uses a qualitative descriptive method because in his research, researchers use more \or discuss words.. Based on the results in this study, researchers found some data that researchers examined about the conjuncture grammatical cohesion in the discourse of the novel by Ayah Hirata's father. The results of the research include some of the conjunctions that we analyze through Alwi's theories that analyze in terms of syntax. The data is in the form of identification of conjunctions that have been mapped according to each conjunction. Conjunctions that can be found in the form of coordinative conjunctions, subordinative conjunctions, correlative conjunctions, conjunctions between sentences, and conjunctions between paragraphs. Of the several conjunctions, there are still mapped back to several conjunctions included in it. It is hoped that this research can become a benchmark in other studies relating to the grammatical cohesion of conjunctions in discourse. So that in research on Conjunction Grammatical Cohesion Analysis in Novel Father Andrea Hirata's Discourse can be useful for all people.
\end{abstract}

Keywords: novel; ayah; andrea hirata; conjunction; grammatical cohesion; discourse

Abstrak: Sebuah novel biasanya menceritakan tentang kehidupan manusia dalam berinteraksi dengan lingkungan dan sesamanya. Tujuan penelitian ini adalah mendeskripsikan jenis konjungsi yang terdapat dalam novel Ayah karya Andrea Hirata dan fungsi bahasa pada konjungsi yang terdapat dalam novel Ayah karya Andrea Hirata. Metode penelitian ini menggunakan metode deskriptif kualitatif. Sumber data dalam penelitian ini berupa novel Ayah karya Andrea Hirata. Teknik pengumpulan data memakai teknik simak cacat yaitu membaca serta mengamati lalu mencatat hasil penelitian tentang kohesi gramatikal konjungsi dalam wacana novel tersebut. Hasil penelitian menunjukkan bahwa terdapat konjungsi koordinatif, konjungsi subordinatif, konjungsi korelatif, konjungsi antar kalimat, dan konjungsi antar paragraf. Dari beberapa konjungsi tersebut masih ada yang dipetakan kembali menjadi beberapa konjungsi yang termasuk di dalamnya. Diharapkan penelitian ini bisa menjadi tolak ukur dalam penelitian lain yang berkaitan dengan kohesi gramatikal konjungsi dalam wacana. Sehingga dalam

Sitasi Jurnal:

Saputro, A., \& Sevira, E. (2020). Analisis Kohesi Gramatikal Konjungsi dalam Wacana Novel Ayah Karya Andrea Hirata. Disastra: Jurnal Pendidikan Bahasa dan Sastra Indonesia, 2(1), 75-85. doi:http://dx.doi.org/10.29300/disastra.v2i1.2536 
penelitian tentang Analisis Kohesi Gramatikal Konjungsi dalam Wacana Novel Ayah Karya Andrea Hirata dapat bermanfaat bagi semua masyarakat.

Kata Kunci: novel; ayah; andrea hirata; kohesi gramatikal; konjungsi; wacana

\section{Pendahuluan}

Novel merupakan salah satu bentuk dari karya sastra. Novel juga dapat diartikan sebuah cerita fiksi yang dituangkan dalam bentuk tulisan atau katakata dan mempunyai unsur instrinsik dan ekstrinsik. Sebuah novel biasanya menceritakan tentang kehidupan manusia dalam berinteraksi dengan lingkungan dan sesamanya. Dalam sebuah novel, pengarang berusaha semaksimal mungkin untuk mengarahkan pembaca kepada gambaran-gambaran realita kehidupan melalui cerita yang terkandung dalam novel tersebut. Sebagian besaar karya sastra novel menggambarkan kejadian yang terjadi di lingkungan masyarakat dan digambarkan dengan sedemian kuat agar pembaca penasaran dan ingin menyelesaikan karya yang sedang dibaca (Seles, 2019). Novel atau sering disebut roman adalah suatu cerita prosa fiktif dalam panjang tertentu yang melukisan para tokoh, gerak, serta adegan nyata yang representatif dalam suatu alur atau keadaan yang agak kacau atau kusut. Karya sastra berupa novel merupakan sarana yang sangat baik untuk membentuk akhlak murid dengan hikmah atau amanat yang terkandung dalam novel (Randi, 2019). Manusia dapat membentuk kalimat-kalimat yang saling berkaitan dan menjadi suatu satu kesatuan disebut wacana.

Kridalaksana (2008:208) menyatakan bahwa wacana adalah satuan bahasa lengkap; dalam hierarki gramatikal merupakan satuan gramatikal tertinggi atau terbesar. Wacana ini direalisasikan dalam bentuk karangan yang utuh (novel, buku, seri ensiklopedia, dan sebagainya), paragraf, kalimat, atau kata yang memiliki isi, makna dan amanat yang lengkap. Dalam sebuah wacana, baik wacana tulis maupun wacana lisan, tersusun dari unsurunsur kata, frasa, klausa, dan kalimat yang membentuk kepaduan informasi yang utuh. Pengaitan sebuah kalimat dengan kalimat lain di dalam sebuah wacana dapat dilakukan dengan sarana atau alat, salah satunya adalah konjungsi. Konjungsi adalah kategori yang menghubungkan kata dengan kata, klausa dengan klausa, atau kalimat dengan kalimat, bisa juga antara paragraf dengan paragraf (Chaer, 2009:8182).

Wacana merupakan bentuk komunikasi anatara penulis dan pembaca (Hoey dalam Haris dan Yunus, 2014: 848). Wacana yang baik adalah wacana yang harus memperhatikan hubungan antara kalimat. Analisis wacana memiliki peranan yang sangat penting dalam pembelajaran bahasa terutama dalam keterampilan berbahasa yang bersifat produktif, yaitu berbicara dan menulis. Menulis merupakan kemampuan menggunakan pola-pola bahasa secara tertulis untuk mengungkapkan suatu gagasan atau pesan. (Andayani, 2015: 191).

$$
\text { Halliday dan Hasan }
$$

mengemukakan bahwa kohesi gramatikal merupakan hubungan kohesi yang dicapai melalui penggunaan elemen dan aturan 
gramatikal, meliputi referensi, substitusi, elipsis, dan konjungsi.

Hal ini harus selalu diperhatikan untuk memelihara keterkaitan dan keruntutan anatarkalimat dalam sebuah paragraf. Pandangan selama ini menyatakan bahwa bahasa itu terdiri atas bentuk dan makna. Dalam hubungan wacana dapat dibedakan menjadi dua jenis yaitu bentuk yang disebut kohesi, dan hubungan makna atau hubungan semantis yang disebut koherensi. Koherensi memegang pernan yang sangat penting dalam pemahaman sebuah wacana berakitan dengan itu kohesi dibedakan menjadi dua yaitu kohesi gramatikal dan kohesi leksikal sehingga digunakan sebuah alat yang disebut penanda kohensi.

Penelitian ini menggunakan teori dari Alwi untuk menganalisis data yang di dapat oleh peneliti melalui novel yang berjudul Ayah karya Andrea hirata. Teori tersebut tentang kohesi gramatikal konjungsi yang dinyatakan oleh Alwi (1993: 236) bahwa dilihat dari segi sintatiknya, konjungsi dibagi menjadi konjungsi koordinatif, konjungsi subordinatif, konjungsi korelatif, konjungsi antarkalimat, dan konjungsi antarparagraf. Peneliti tertarik meneliti penelitian tersebut karena dilihat dari fenomena penulisan sebuah karya novel tidak terlepas dari adanya konjungsi yang merupakan kata hubung untuk memperlengkap sebuah kalimat. Maka peneliti ingin mengidentifikasi konjungsi apa saja yang terdapat dalam novel tersebut terlepas dari jalan cerita novel tersebut.

Penelitian terdahulu yang berkaitan dengan kajian analisis wacana khususnya pada pembahasaan tentang analisis kohesi gramatikal konjungsi dalam wacana novel Ayah karya Andrea Hirta diantaranya sebagai berikut.

Dwi Susanti (2014) dengan judul "Analisis Kohesi Gramatikal Konjungsi dalam Wacana Novel Burung-Burung Cakrawala Karya Mochtar Pabottingi". Penelitian ini bertujuan untuk mengkasifikasikan jenis konjungsi yang terdapat dalam novel Burung-Burung Cakrawala karya Mocthar Pabottingi dan mendeskripsikan fungsi bahasa pada konjungsi yang terdapat dalam novel Burung-Burung Cakrawala karya Mocthar Pabottingi. Penelitian ini memiliki jenis penelitian deskriptif kualitatif. Hasil penelitian pada jurnal ini adalah konjungsi pada novel Burung-Burung Cakrawala karya Mochtar Pabottingi terbagi menjadi dua jenis konjungsi, yaitu konjungsi koordinatif dan konjungsi subordinatif. Pada konjungsi koordinatif terdapat konjungsi dan, serta, adalah, atau, melainkan, maka, lalu, kecuali, namun, tetapi, dan mula-mula. Pada konjungsi subordinatif terdapat konjungsi setelah, sesudah, seperti, dan sejak. fungsi-fungsi bahasa yang terdapat pada novel BurungBurung Cakrawala karya Mochtar Pabottingi terdiri dari fungsi informasional, fungsi puitik, dan fungsi ekspresif.

Endang Wiyanti (2016) dengan judul "Kohesi Gramatikal Konjungsi Wacana Kolom Hikmah dalam Surat Kabar Republika". Penelitian ini bertujuan untuk mendeskripsikan data empiris kohesi gramatikal konjungsi wacana kolom "Hikmah" surat kabar Republika dan untuk melihat kekohesifan wacana kolom "Hikmah" surat kabar Republika dari aspek 
Volume 2, Nomor 1, Januari 2020

ISSN 2655-3031 (P), 2655-7851 (O)

kohesi gramatikal konjungsi. Metode penelitian adalah metode studi analisis isi. Data dalam bentuk dua puluh lima judul wacana kolom "Hikmah" yang terbit pada bulan Agustus 2015 dipilih secara acak dari 286 judul wacana. Teknik pengumpulan data yang digunakan dalam penelitian ini adalah dengan studi pustaka, yaitu dengan melakukan penelitian dan pengumpulan data ke Pusat data harian umum Republika pada 13 April 2016. Langkah-langkah analisis data dilakukan dengan menentukan teks, dekontekstualisasi, menentukan pasangan berdekatan, menulis pasangan, analisis masing-masing pasangan, rekapitulasi, dan mendeskripsikan hasil analisis.

Penelitian ketiga, penelitian skripsi oleh Wahid Abdul Rohman (2013) dengan judul "Analisis Kohesi Gramatikal Konjungsi pada Teks Terjemahan Al-Quran Surat Al-Azhab". Penelitian ini bertujuan untuk Penelitian ini menganalisis bentuk kohesi gramatikal konjungsi yang digunakan pada teks terjemahan Alquran surah Al Ahzab. Kohesi dalam sebuah wacana diartikan sebagai kepaduan bentuk yang secara struktural membentuk ikatan sintakitikal. Kohesi sebuah wacana terbagi kedalam dua aspek, yaitu kohesi gramatikal dan kohesi leksikal. Dalam penelitian ini yang akan dikaji adalah kohesi gramatikal, kususnya kohesi gramatikal konjungsi. Teks terjemahan Alquran adalah salah satu objek kajian wacana yang banyak mengandung kohesi gramatikal konjungsi. Tujuan yang akan dicapai dalam penelitian ini ada dua. 1) Mendeskripsikan jenis dan bentuk kohesi gramatikal konjungsi yang digunakan pada teks terjemahan Alquran surah Al Ahzab. 2)Memaparkan makna yang terkandung dalam surah Al Ahzab. Bentuk penelitian yang digunakan adalah bentuk penelitian kualitatif deskriptif. Teknik yang digunakan untuk mengumpulkan data adalah teknik simak dan catat. Teknik yang digunakan untuk menganalisis data dalam penelitian ini menggunakan metode padan intralingual. Hasil penelitian ini terdapat dua macam bentuk konjungsi. 1) Konjungsi koordinatif. 2) Konjungsi subordinatif.

Dari ketiga penelitian tersebut dapat disimpulkan bahwa terdapat beberapa perbedaan. Perbedaan tersebut terlihat dari sumber data, masalah yang diteliti, dan teknik pengumpulan data. Dalam penelitian terdahulu menggunakan sumber data berupa teks terjemahan Al-Quran dalam surat Al-Azhab, surat kabar, dan novel yang berbeda judul yang sangat berbeda dengan penelitian yang sekarang yang memperoleh sumber data dari novel Ayah karya Andrea Hirata. Kemudian, sumber data pada penelitian yang sekarang menggunakan novel yang berjudul Ayah karya Andrea Hirata. Selanjutnya teknik pengumpulan data pada penelitian terdahulu menggunakan teknik observasi data atau dokumen dan triangulasi. Sedangkan pada penelitian yang sekarang menggunakan teknik analisis pada dokumen. Persamaan penelitian terdahulu dengan penelitian yang sekarang yaitu sama-sama menggunakan metode deskriptif kualitatif.

Berdasarkan paparan tersebut penulis tertarik untuk menganalisis kohesi gramatikal yang difokuskan pada penggunaan konjungsi. Peneliti mengambil 
data dari wacana novel Ayah karya Andrea Hirata. Berdasarkan latar belakang masalah di atas terdapat dua rumusan masalah yang dibahas dalam penelitian ini. Pertama, apa saja jenis konjungsi yang terdapat dalam novel Ayah karya Andra Hirata. Kedua, Bagaimana fungsi bahasa pada konjungsi yang terdapat dalam novel Ayah karya Andrea Hirata.

\section{Metode Penelitian}

Dalam penelitian ini penulis menggunakan metode deskriptif kualitatif. Menurut Mukhtar (2013:10) menyatakan bahwa metode deskriptif kualitatif merupakan sebuah metode atau cara yang digunakan peneliti untuk menemukan pengetahuan atau teori terhadap penelitian pada waktu tertentu. Melalui metode terebut peneliti mencoba memaparkan analisis tentang kohesi gramatikal konjungsi pada sebuah novel yang berjudul Ayah karya Andrea Hirata. Langkah kerja pada metode ini adalah menganalisis dan mendeskripsikan kohesi gramatikal konjungsi pada novel yang berjudul Ayah karya Andrea Hirata.

Teknik pengumpulan data yang digunakan dalam penelitian ini adalah analisis data dokumen yang berupa novel yang berjudul Ayah karya Andrea Hirata. Analisis data dokumen tersebut diperoleh dari teknik simak dan teknik catat. Data yang sudah disimak atau dianalisis tersebut lalu dicatat dan dituangkan kedalam bentuk dokumen hasil analisis. Tahap analisis data ini mengacu pada tahap pengamatan dan pembedahan pada suatu masalah yang akan diteliti. Pada tahap analisis data, peneliti menggunakan teknik ketekunan pengamatan. Selanjutnya teknik yang dilakukan adalah teknik catat dari apa yang saja yang peneliti temukan pada analisis kohesi gramatikal konjungsi pada novel berjudul Ayah karya Andrea Hirata.

Teknik analisis menggunakan analisi model interaktif berupa reduksi data, pengumpulan data, dan penarikan kesimpulan. Alur yang pertama reduksi data yaitu data yang sudah ditemukan kemudian di reduksi dan di pilah-pilah sesuai dengan bagian yang terpenting. Pengumpulan data ini untuk memudahkan dalam penyajian dan penarikan kesimpulan.

Alur yang kedua penyajian data yaitu data yang sudah terkumpul kemudian dikelompokkan menurut jenisnya untuk mengetahui keselarasan dengan permasalahan yang dihadapi. Jadi pada alur kedua ini data peneliti dikumpulkan kemudian di seleksi dialog mana yang di dalamnya terdapat kohesi gramatikal konjungsi. Alur yang ketiga simpulan yaitu penarikan simpulan yang disusun berdasarkan data yang diperoleh untuk mencari hasil dari data yang sudah dikumpulkan. Jadi pada alur ketiga ini data yang disajikan dalam penelitian ini berupa tabel yang telah dikelompokkan menjadi kohesi gramatikal konjungsi. Setelah semua data dikelompokkan ke dalam tabel, kemudian di analisis satu per satu sesuai dengan jenis kohesi gramatikal konjungsinya, setelah itu dapat ditarik kesimpulan. 


\section{Hasil dan Pembahasan}

\section{Analisis Kohesi Gramatikal Konjungsi dalam Wacana Novel Ayah Karya Andrea Hirata}

Alwi (1993: 236) melihat dari segi sintatiknya, konjungsi dibagi menjadi konjungsi koordinatif, konjungsi subordinatif, konjungsi korelatif, konjungsi antarkalimat, dan konjungsi antarparagraf. Konjungsi koordinatif adalah konjungsi yang menghubungkan dua unsur kalimat atau lebih yang kedudukannya sederajat atau setara.

\section{Konjungsi koordinatif aditif \\ Data 1}

Anak dan ayah itu menuju dermaga untuk menyaksikan matahari terbenam. (hlm 65)

Sebanarnya, dia menyanyikan puisi merayu awan dan dia menginginkan ayahnya. (hlm 236)

Lalu menjulurkan tangannya menerima kemeja itu, dicium dan dipeluknya kemeja itu. (hlm 236)

Lena, betapa sahabatnya itu telah berekelana dan tak pernah ragu untuk menjadi dirinya sendiri. (hlm 245)

Dari kutipan diatas dapat diambil simpulan bahwa kata dan termasuk kedalam konjungsi koordinatif aditif yang terdapat dalam novel Ayah karya Andrea Hirata.

\section{Konjungsi koordinatif adversatif}

Konjungsi koordinatif adversative merupakan konjungsi yang menghubungkan dua unsur wacana yang sederajat dan kontras.

\section{Data 2}

Si bungsu itu sempat mau dinamai Tobati, tetapi nama itu keburu diambil sepupu ibu Sabari. (hlm 61) Bergegas ke kamar lagi, tetapi terkejut karena Zorro tak ada. (hlm 238).

Lena dan minta ampun macam orang Lebaran, tetapi Lena adalah perempuan besi dengan pendirian yang lebih tegak dari pada tiang bendera di Lapangan Merdeka. (hlm 265)

Dari Analisis diatas dapat diambil simpulan bahwa kata tetapi termasuk kedalam konjungsi koordinatif adversatif yang terdapat dalam novel Ayah karya Andrea Hirata.

\section{Konjungsi koordinatif pemilihan}

Konjungsi koordinatif pemilihan merupakan konjungsi yang menghubungkan dua unsur yang sederajat dan fungsinya menyatakan pilihan.

Data 3

Yang bisa dilakukannya hanya menunggu wangsit atau tandatanda. (hlm 124)

Di statiun kereta, pelabuhan, atau bangku-bangku terminal. (hlm 268)

Dari Analisis diatas dapat diambil simpulan bahwa kata atau termasuk kedalam konjungsi koordinatif pemilihan yang terdapat dalam novel Ayah karya Andrea Hirata. Konjungsi subordinatif adalah konjungsi yang menghubungkan dua unsur kalimat (klausa) yang kedudukannya sederajat.

\section{Konjungsi subordinatif waktu}

Data 4

Sebelumnya 
Volume 2, Nomor 1, Januari 2020

ISSN 2655-3031 (P), 2655-7851 (O)

Sebelumnya, ku pun pernah bilang bahwa dia suka sama Sita, Mawar, Anisa, dll. (hlm 10.)

Dari Analisis diatas dapat diambil simpulan bahwa kata Sebelumnya termasuk kedalam konjungsi subordinatif waktu yang terdapat dalam novel Ayah karya Andrea Hirata

\section{Data 5}

Sementara

Sementara itu, nun dipojok selasar itu Sabari yang belum sadar dari pukau saat Lena datang. (hlm 34)

Untuk sementara dia menjadi tukang jahit. (hal 149)

Dari Analisis diatas dapat diambil simpulan bahwa kata Sementara termasuk kedalam konjungsi subordinatif waktu yang terdapat dalam novel Ayah karya Andrea Hirata.

\section{Data 6}

Sejak

Sejak saat itu, setiap menjelang tidur tak jemu-jemu Sabari meminta ayahnya bercerita. (hlm 63)

Sejak saat itu, menjelang tidur, tak jemu-jemu Sabari meminta ayahnya bercerita tentang keluarga langit dan melantunkan nyanyian untuk merayu awan. (hlm 63)

Dari Analisis diatas dapat diambil simpulan bahwa kata Sejak termasuk kedalam konjungsi subordinatif waktu yang terdapat dalam novel Ayah karya Andrea Hirata.

\section{Data 7}

Setelah

Dia pernah kena stroke ringan.

Setelah itu, dia memakai kursi roda. (hlm 63)
Amiru menantap para pembalap yang mengambil nomor lomba. Setelah agak sepi, dia memberanikan diri untuk mendaftar. (hlm 92)

Setelah Lagu Kebangsaan, akan mengudara siaran yang ditunggu ayahnya itu. (hlm 134)

Setelah berminggu-minggu dia bisa mengisi jeriken minyak tanah sepuluh liter.(hal 139)

Setelah menimbang segala hal, akhirnya. (hal 140)

Setelah mempertimbangkan berbagai aspek, mereka memutuskan untuk mencari Lena dan Zoro. (hlm 286)

Dari Analisis diatas dapat diambil simpulan bahwa kata Setelah termasuk kedalam konjungsi subordinatif waktu yang terdapat dalam novel Ayah karya Andrea Hirata.

\section{Konjungsi subordinatif syarat \\ Data 8 \\ Jika \\ Jika ada berita Lady Diana mengunjungi kampung miskin nun dibelahan dunia antah-berantah. (hlm 7) \\ Dia menunggu seluruh siswa pulang. Dia sudah punya rencana, jika angka merah dirapornya ada empat atau lebih. (hlm 82)}

Dari Analisis diatas dapat diambil simpulan bahwa kata tetapi termasuk kedalam konjungsi subordinatif syarat yang terdapat dalam novel Ayah karya Andrea Hirata. 
Data 9

Kalau

Kalau Lena main kasti, tak tahu siapa yang menyuruhnya. (hlm 37) Jika terbangun cepat-cepat dilihatnya Zorro, kalau sudah tak ada.

Dari Analisis diatas dapat diambil simpulan bahwa kata kalau termasuk kedalam konjungsi subordinatif syarat yang terdapat dalam novel Ayah karya Andrea Hirata.

\section{Konjungsi subordinatif tujuan}

Data 10

Agar

Agar sasaran tak lolos, Sabari mengambil posisi dipinggir selasar. (hlm 32)

Ukun menyarankan agar Sabari minta maaf kepada Lena dan Bogel secara terbuka. (hlm 95)

Dari Analisis diatas dapat diambil simpulan bahwa kata agar termasuk kedalam konjungsi subordinatif tujuan yang terdapat dalam novel Ayah karya Andrea Hirata.

\section{Konjungsi subordinatif konsesif}

Data 11

Walaupun

Diam-diam dia masuk ke kelas sebelah dan berjumpa dengan Lena, walaupun hanya dalam bentuk bangkunya yang kosong. (hlm 83)

Dari Analisis diatas dapat diambil simpulan bahwa kata walaupun termasuk kedalam konjungsi subordinatif konsesif yang terdapat dalam novel Ayah karya Andrea Hirata.

\section{Konjungsi subordinatif pembandingan Data 12}

Sebagai

Sebagai Sabari telah diajari ayahnya untuk membaca tanda-tanda, sebagai bagian darinya istimewanya puisi. (hlm 64)

Dari Analisis diatas dapat diambil simpulan bahwa kata sebagai termasuk kedalam konjungsi subordinatif pembandingan yang terdapat dalam novel Ayah karya Andrea Hirata.

\section{Konjungsi subordinatif sebab Data 13}

\section{Karena}

Gambar-gmbar hitam putih, karena sudah lama tentu saja, silih berganti melayang dalam kepala lelaki lugu yang melankolis itu. (hlm. 3)

Suhu pernapasan, detak jantung, semua diperiksa. Kamar Ibu nanti tidak panas karena ada AC. (hlm 90)

Dari Analisis diatas dapat diambil simpulan bahwa kata karena termasuk kedalam konjungsi subordinatif sebab yang terdapat dalam novel Ayah karya Andrea Hirata.

\section{Data 14}

Sebab

Itulah sebabnya ayahku menamaiku

Tamat. (hlm 11)

Dan tak terbilang girangnya Sabari sebab sebagian besar soal geometri adalah tentang kerucut dan berbagai implikasi rumusannya. (hlm 84)

Dari Analisis diatas dapat diambil simpulan bahwa kata sebab termasuk kedalam konjungsi subordinatif sebab 
yang terdapat dalam novel Ayah karya Andrea Hirata.

\section{Data 15}

Oleh karena

Oleh karena itu, dia selaku anak tertua juga selalu rajin merawat ibunya. (hlm 14)

Oleh karena itu, banyak yang tak betah bekerja dengannya.

Dari Analisis diatas dapat diambil simpulan bahwa kata oleh karena termasuk kedalam konjungsi subordinatif sebab yang terdapat dalam novel Ayah karya Andrea Hirata.

\section{Konjungsi subordinatif hasil}

Data 16

Sehingga

Radio kuno yang tutup belakangnya tak tahu sudah minggat kemana, sehingga tampak rangkaian kabel berkelok-kelok semaunya. (hlm. 5)

Dari Analisis diatas dapat diambil simpulan bahwa kata sehingga termasuk kedalam konjungsi subordinatif hasil yang terdapat dalam novel Ayah karya Andrea Hirata.

\section{Data 17}

Maka

Maka nol persen, itulah peluangmu. (hlm 39)

Maka, secara resmi hubungannya dengan Lena, Khatam. (hlm 88)

Dari Analisis diatas dapat diambil simpulan bahwa kata maka termasuk kedalam konjungsi subordinatif hasil yang terdapat dalam novel Ayah karya Andrea Hirata.

\section{Konjungsi subordinatif alat \\ Data 18}

Dengan

Dengan berat hati Amirza membukus radio itu. (hlm 53)

Dari Analisis diatas dapat diambil simpulan bahwa kata dengan termasuk kedalam konjungsi subordinatif alat yang terdapat dalam novel Ayah karya Andrea Hirata.

\section{Konjungsi subordinatif cara}

\section{Data 19}

Dengan

Dengan cepat, usaha batakonya mengalami kemajuan. (hlm 26)

Dari Analisis diatas dapat diambil simpulan bahwa kata dengan termasuk kedalam konjungsi subordinatif cara yang terdapat dalam novel Ayah karya Andrea Hirata.

\section{Konjungsi subordinatif komplemtasi} Bahwa

Markoni selalu mengatakan sesuatu yang dikatakan ayahnya kepadanya dulu bahwa jika anaknya mau sekolah. (hlm 28)

Menunjukkan bahwa ayahnya memberi restu kepadanya untuk pacaran. (hlm 124)

Bahwa es bukanlahh sekedar benda mati yang dingin jika disentuh. (hal 141)

Dari Analisis diatas dapat diambil simpulan bahwa kata bahwa termasuk kedalam konjungsi subordinatif komplemtasi yang terdapat dalam novel Ayah karya Andrea Hirata. 
Konjungsi subordinatif atribut

Data 21

Yang

Seorang kawan terdekat Lena, Zuraida, yang senang saja disogok Sabari dengan buah nangka hasil kebun sendiri. (hlm 40)

Melainkan sebuah benda yang banyak sekali membuka lapangan kerja bagi orang susah. (hal 141)

Dari Analisis diatas dapat diambil simpulan bahwa kata yang termasuk kedalam konjungsi subordinatif atribut yang terdapat dalam novel Ayah karya Andrea Hirata.

\section{Konjungsi korelatif}

Konjungsi korelatif merupakan konjungsi yang menghubungkan dua kata, frasa, atau klausa dan kedua unsur itu memiliki status sintaksis yang sama. Konjungsi korelatif terdiri atas dua bagian yang dipisahkan oleh satu kata, frasa, atau klausa yang dihubungkan.

\section{Data 22}

Bahwa es bukanlah sekedar benda biasa, tetapi juga berjada dalam mengurangi penderitaan ikan-ikan.

Dari analisis di atas dapat diiambil simpulan kata bahwa dan tetapi termasuk kedalam konjungsi korelatif karena konjungsi yang mengubungkan dua kata, frasa, atau klausa dalam novel Ayah karya Andrea Hirata.

\section{Konjungsi antar kalimat}

Konjungsi antar kalimat adalah konjungsi yang menghubungkan satu kalimat dengan kalimat yang lain.

\section{Data 23}

Sabari menyapu ruang olah raga dengan gesit, meski hari itu bukan jadwal piketnya. Setelah itu, dia membuka baju lalu berlari mengelilingi lapangan upacara. (hlm 75)

Zuraida kemudian menyampaikan kepada Ismi bahwa Sabari menjadi guru Bahasa Indonesia seperti ayahnya. (hlm 81)

Dari Analisis diatas dapat diambil simpulan bahwa kata kemudian, setelah termasuk kedalam konjungsi antar kalimat yang terdapat dalam novel Ayah karya Andrea Hirata.

\section{Konjungsi antar paragraf}

Konjungsi antar paragraf merupakan konjungsi yang digunakan untuk menghubungkan paragraf tempat konjungsi itu dipakai dengan paragraf sebelumnya.

\section{Data 24}

Di antara kawan-kawan kerjanya, Manikam selalu mengatakan bahwa mereka adalah pegawai yang digaji dengan uang rakyat, penerima amanah yang tak boleh sembarangan saja bertabiat.

Adapun Boros Akinmusire, pemain trompet dalam Setia Nada berkata, “ Repot sekali kalau ada Bang, Jon, ngomel saja kerjanya. (hlm 294)

Dari Analisis diatas dapat diambil simpulan bahwa kata adapun termasuk kedalam konjungsi antar paragraf yang terdapat dalam novel Ayah karya Andrea Hirata.

\section{Simpulan}

Dari pembahasan di atas dapat disimpulkan bahwa kohesi gramatikal konjungsi yang terdapat dalam novel Ayah 
Volume 2, Nomor 1, Januari 2020 ISSN 2655-3031 (P), 2655-7851 (O)

karya Andrea Hirata memiliki beberapa konjungsi yang dapat dianalisis menurut kohesi gramatikal konjungsi dari segi sintaksisnya. Konjungsi tersebut mencakup konjungsi koordinatif, konjungsi subordinatif, konjungsi korelatif, konjungsi antar kalimat, konjungsi antar paragraf. Dari analisis kohesi gramatikal konjungsi tersebut, dapat dilihat bahwa konjungsi yang paling banyak digunakan dalam penulisan novel Ayah karya Andrea Hirata tersebut adalah konjungsi subordinatif.

\section{Daftar Pustaka}

Ansayani, 2015. Problema dan Aksioma dalam Metodologi Pembelajaran Bahasa Indonesia. Yogyakarta :Deepublish.

Chaer, Abdul. 2009. Sintaksis Bahasa Indonesia: Pendekatan Proses. Jakarta: Rineka Cipta.

Damono. 1979. Novel Sastra Indonesia Sebelum Perang. Jakarta. Pusat Pembinaan dan Pengembangan Bahasa

Kridalaksana, Harimurti. 2008. Kamus Linguistik. Jakarta: Gramedia

Randi, R. (2019). Aspek Religius dan Moral Novel 99 Cahaya Di Langit Eropa Karya Hanum Salsabiela Rais Dalam Pembelajaran Apresiasi Sastra di Sekolah Menengah Atas. Disastra: Jurnal Pendidikan Bahasa dan Sastra Indonesia, 1(1), 71-76. doi:http://dx.doi.org/10.29300/disastr a.v1i1.1825

Ratna, Nyoman Kutha. 2010. Stilistika Kajian Puitika Bahasa, Sastra, dan Budaya. Yogyakarta: Pustaka Pelajar
Seles, S. (2019). Analisis Perbandingan Novel "Mutiara di Kota Melbourne" dan "Four Seasons In Belgium" dengan Pendekatan Mimetik. Disastra: Jurnal Pendidikan Bahasa dan Sastra Indonesia, 1(1), 33-40. doi:http://dx.doi.org/10.29300/disastr a.v1i1.1463

Semi, Atar M. 2012. Metode Penelitian Sastra. Bandung: Angkasa.

Sudjiman, Panuti. 1986. Kamus Istilah Sastra. Jakarta. Gramedia

Taum. 1997. Pengantar Teori Sastra: Eksprensivisme, Strukturalisme, Pascastrukturalisme, Sosiologi, Resepsi. Ende. Nusa Indah 